\title{
Failure to detect platelet-activating factor using the splenectomized mouse bioassay
}

\author{
J. M. Scodras, K. J. Betteridge, B. A. Croy, I. B. Johnstone and D. Rieger \\ Department of Biomedical Sciences, Ontario Veterinary College, University of Guelph, Guelph, \\ Ontario, Canada, NIG $2 \mathrm{Wl}$
}

\begin{abstract}
Summary. The ability of purified preparations of platelet-activating factor (PAF), from three different suppliers, to induce thrombocytopaenia in mice after splenectomy and to activate mouse platelets in vitro was examined. Although the PAF preparations were potent activators of horse and cow platelets in vitro, injections of up to $1 \mu \mathrm{g}$ PAF failed to elicit thrombocytopaenic responses in either CD1 or Swiss Webster random-bred mice. However, when thrombin was injected into Swiss Webster mice, a dosedependent decrease in the concentration of platelets was observed. Furthermore, isolated platelets from these strains and from 3 inbred lines $(\mathrm{C} 3 \mathrm{H} / \mathrm{He}, \mathrm{BALB} / \mathrm{c}, \mathrm{C} 57 \mathrm{BL} / 6)$ of mice, were not aggregated by PAF in vitro but were sensitive to adenosine diphosphate and thrombin. No change in circulating platelet concentrations was observed over the initial 7 days of gestation in intact Swiss Webster and $\mathrm{C} 57 \mathrm{BL} / 6$ or splenectomized $\mathrm{C} 57 \mathrm{BL} / 6$ mice, suggesting either an absence of PAF production during early pregnancy in these strains or insensitivity of their platelets to PAF. These results suggest that many mouse strains are unsuitable for the bioassay of PAF.
\end{abstract}

Keywords: platelet-activating factor; thrombocytopaenia; aggregometry; bioassay; embryonic viability; mouse

\section{Introduction}

In mice, a thrombocytopaenic response (i.e. decrease in the concentration of circulating blood platelets) has been reported to occur as soon as $6 \mathrm{~h}$ after fertilization and to persist throughout the first week of pregnancy (O'Neill, 1985a). A similar thrombocytopaenic response can be induced in nonpregnant mice by intraperitoneal administration of platelet-activating factor (PAF-acether; O'Neill, 1985c). Both mouse and human preimplantation embryos between the zygote and the blastocyst stages are reported to release a potent platelet-activating factor (O'Neill et al., 1985b; Spinks \& O’Neill, 1987; O'Neill et al., 1987), which has similar biochemical and biological properties to the ether phospholipid PAF-acether (O'Neill, 1985b).

Platelet-activating factor has been quantitated in a bioassay using splenectomized mice of the Quackenbush strain (O'Neill et al., 1985a; 1987). Removal of the spleen is necessary because this organ acts as a reservoir for platelets and can release them into the circulation by splenic contraction. This can mask reductions in the circulating platelet population and result in false negative responses in the bioassay (O'Neill, 1985c).

Studies using antagonists of PAF have demonstrated the importance of embryo-derived PAF in the establishment of pregnancy in mice (Spinks \& O'Neill, 1987, 1988). In humans, the PAF production from in-vitro fertilized embryos, measured with the bioassay using Quackenbush mice, can be used to determine embryo viability prior to embryo transfer and to monitor embryo survival (O'Neill \& Saunders, 1984; O'Neill et al., 1985b). Such a quantitative method for the evaluation of embryonic viability would be of great benefit to the cattle embryo transfer industry, since the rate of loss of morphologically normal embryos following transfer is often $>40 \%$ (Betteridge, 1986). 
However, since the Quackenbush mouse strain is not readily available in North America, and in the light of evidence concerning the insensitivity of platelets from some mouse strains to PAF (Namm et al., 1982), the present study was undertaken to determine whether PAF detection is possible using several more readily available strains of laboratory mice.

\section{Materials and Methods}

\section{Experimental animals}

Mice. Two random-bred mouse strains, Swiss Webster and CDI, and three inbred mouse strains, $\mathrm{C} 3 \mathrm{H} / \mathrm{He}$, C57BL/6 and BALB/c, were obtained from Charles River Laboratories (St Constant, Quebec, Canada) at 4-6 weeks of age. All were housed at $21^{\circ} \mathrm{C}$ under a 12-h light/12-h dark cycle for at least 2 weeks before use. Food and water were provided ad libitum. Pregnancies were established in either Swiss Webster or C57Bl/6 mice by placing 2 females with one male of the same genotype. The morning of vaginal plug detection was referred to as Day 0 following removal from the mating cage. Mice in which no vaginal plug was detected were considered unmated and not pregnant, unless upon autopsy their uteri were inflamed or contained foetuses.

Cows and horses. Mature standard-bred mares from the Ontario Veterinary College teaching program and normal, reproductively sound, Holstein heifers from a research embryo donor herd were used as blood donors in this study.

\section{Anaesthetics and surgical procedures}

Methoxyflurane inhalation (Metofane; Pitman-Moore Ltd, Washington Crossing, NJ, USA) was used to induce light anaesthesia in mice; $1 \mathrm{ml}$ of metofane was poured onto an absorbent pad in the bottom of a $1 \cdot 5$-litre jar and the mouse was placed on a suspended wire platform within the jar for $1.5-2 \mathrm{~min}$. The mice regained consciousness within 5 min of treatment.

Deep anaesthesia was achieved with an intraperitoneal injection of $0.2-0.5 \mathrm{ml}$ of a $1.25 \%(\mathrm{w} / \mathrm{v})$ tribromoethanol solution (Aldrich Chemical Company, Milwaukee, WI, USA). The mice remained unconscious for $0.5-1 \cdot 0 \mathrm{~h}$.

For splenectomy, a left paramedial dorsal incision was performed on deeply anaesthetized 8-10-week-old mice. The spleen was drawn from the abdominal cavity with fine blunt forceps. The splenic blood vessels were electrocauterized and the organ was dissected free of adipose tissue and removed. The incision was sutured with 4-0 silk and the mice were placed under a heat lamp for recovery before being returned to normal housing conditions. Splenectomized mice were used in experiments $8-16$ days after surgery.

\section{Blood collection}

Mice. Mice were lightly anaesthetized and blood was drawn from the retro-orbital plexus using $20-\mu$ l capillary tubes for the determination of platelet concentrations, 100- $\mu$ l heparinized capillary tubes for haematocrit measurement, or siliconized Pasteur pipettes for collection of $0.5-1 \mathrm{ml}$ volumes of blood. Blood collected by Pasteur pipette was prepared for platelet isolation by placing it into a $10 \times 75 \mathrm{~mm}$ siliconized glass tube containing sodium citrate (12mm final concentration).

Cows and horses. Blood was collected from the jugular vein through a 14-gauge needle into a $50-\mathrm{ml}$ sterile syringe containing sodium citrate ( $13 \mathrm{~mm}$ final concentration). The blood was then placed into siliconized glass 5 -ml conical tubes for platelet isolation.

\section{Platelet isolation}

Platelet-rich plasma (PRP). Mouse, cow or horse blood containing sodium citrate was centrifuged at $200 \mathrm{~g}$ for $15 \mathrm{~min}$ at room temperature to collect plasma which was rich in suspended platelets.

Platelet-poor plasma (PPP). Following the removal of PRP, the blood was centrifuged at $2000 \mathrm{~g}$ for a further $15 \mathrm{~min}$. The resulting plasma was free of platelets as determined by microscopic examination.

Washed platelets (WP). Some horse platelets were washed free of plasma and resuspended in Tyrode's buffer, pH 7.4 (Fisher Scientific, Fair Lawn, NJ, USA) as described by Suquet \& Leid (1983).

\section{Agents of platelet activation}

Platelet-activating factor (PAF). Purified preparations of PAF were obtained from three suppliers: 1-o-alkyl2-acetyl-sn-glyceryl-3-phosphoryl-choline from Sigma, St Louis, MO, USA: 1-o-hexadecyl-2-acetyl-sn-glycero-3- 
phosphocholine from Boehringer-Mannheim, Dorval, Quebec, Canada and L- $\alpha$-lecithin, $\beta$-acetyl, $\gamma$ - - -alkyl from Calbiochem, San Diego, CA, USA. All PAF preparations were dissolved in ethanol, according to the manufacturers' instructions, and then diluted in Dulbecco's phosphate-buffered saline (PBS; Gibco Laboratories, Grand Island, NY, USA) supplemented with $0.25 \mathrm{~g}$ bovine serum albumin/100 ml (BSA; Sigma, St Louis, MO, USA; O'Neill, 1985b).

Adenosine diphosphate (ADP). ADP (Sigma, St Louis, MO, USA) was dissolved in a Tyrode's-buffered BSA solution, $\mathrm{pH} 7 \cdot 4$, for use in vitro.

Thrombin. Thrombin (Parke Davis, Scarborough, Ontario, Canada) was prepared for in-vitro and in-vivo use in a Tyrode's-buffered BSA solution, $\mathrm{pH} 7 \cdot 4$.

\section{Platelet counting}

Peripheral blood platelet concentrations were determined on retro-orbital blood samples diluted 1:100 with 70mm ammonium oxalate (Unopette system; Becton-Dickinson, Rutherford, NJ, USA). After thorough mixing with the diluent, the blood was allowed to stand for $5 \mathrm{~min}$, then an aliquant was loaded onto a Bright Line haemocytometer (American Optical, Buffalo, NY, USA). The haemocytometer was placed in a humidified chamber and the platelets were given 15.20 min to settle prior to counting (Brecher \& Cronkite, 1950). Platelets appeared as highly refractile small, round to oval, dark bodies with light centres and were counted under phase-contrast microscopic illumination (Carl Zeiss, Don Mills, Ontario, Canada). All platelet counts were performed at least in duplicate and expressed in terms of the concentration of platelets in whole blood.

\section{Experiment 1: determination of variation in platelet concentrations}

Blood taken from both retro-orbital plexuses of one splenectomized female C57BL/6 mouse was loaded into 7 haemocytometers and platelet concentrations were determined for each replicate.

\section{Experiment 2: determination of circulating platelet concentrations during pregnancy}

Ten pregnant Swiss Webster and 10 C57BL/6 female mice were used to measure circulating platelet concentrations during early pregnancy. For each mouse, blood samples for the determination of platelet concentrations were taken on Days $0,1,4$, and 7 following removal from the mating cage. The mice were killed on Day 7 and their reproductive tracts were examined for the presence of embryos. Ten nonpregnant female mice of each strain were bled at the same time as the pregnant mice to provide control samples.

The effect of splenectomy on the detection of thrombocytopaenia during early pregnancy was studied in a similar manner, using 3 pregnant and 3 nonpregnant splenectomized female C57BL/6 mice.

\section{Experiment 3a: evaluation of the splenectomized mouse bioassay}

Thirty Swiss Webster and $30 \mathrm{CD} 1$ female mice were prepared for use in the PAF bioassay as described by O'Neill 't al. (1985a). Briefly, a pre-injection control platelet concentration was determined for each splenectomized mouse. Syringes containing $200 \mu \mathrm{l}$ of control vehicle (PBS-BSA) or PAF $(2 \cdot 3,4 \cdot 6$ or $9 \cdot 2 \mu \mathrm{M})$ were prepared and coded so that their contents remained unknown until the end of the experiment. The content of each syringe was injected i.p. into an individual splenectomized mouse and a blood sample was obtained $30 \mathrm{~min}$ later. Each treatment was performed on 3 mice and the thrombocytopaenic effect was calculated for each animal by dividing post-injection by pre-injection platelet concentration and multiplying by 100 .

\section{Experiment 3b: estimation of changes in total numbers of circulating platelets during the splenectomized mouse bioassay}

Splenectomized Swiss Webster and CDI mice ( 10 of each strain) were used to measure platelet concentrations and haematocrits in sequential samples taken before and 30 min after 200- $\mu$ l i.p. injections of either control vehicle or PAF

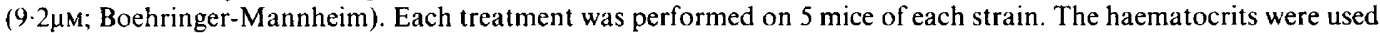
to estimate changes in blood volume and to adjust the post-injection platelet concentration accordingly, so that changes in total numbers of circulating platelets could also be estimated. To do so, the post-injection platelet count was multiplied by the ratio of the pre- to post-injection haematocrits. The percentage change in total platelet numbers was then calculated by dividing corrected post- by pre-injection counts and multiplying by 100 .

\section{Experiment 4: aggregometric assay of the PAF preparations}

A platelet aggregation profiler (Model PAP-2A; Johns Scientific, Toronto, Ontario, Canada) was employed to measure changes in light transmission through a platelet sample during platelet aggregation. The aggregation profiler 
was adjusted to $100 \%$ transmission with a sample of PPP. A 450- $\mu$ l sample of PRP containing $200 \times 10^{9}$ horse or cow platelets $/ 1$ was then placed into the test chamber to set the $0 \%$ transmission reading. A $50-\mu l$ aliquant of PAF ranging from $2 \mathrm{~nm}$ to $8 \mathrm{pm}$ in final concentrations was then added to the PRP sample. The profiler recorded increases in the percentage of light transmitted as platelet aggregation occurred. Fresh dilutions of PAF were prepared and placed either directly into siliconized $12 \times 75 \mathrm{~mm}$ glass tubes or loaded into $1-\mathrm{ml}$ disposable syringes and held for $2 \mathrm{~h}$ at room temperature. A disposable syringe was used as a container for PAF to assess whether PAF was adsorbed onto plastic, thereby interfering with i.p. delivery to mice (see Exp. 3). To increase the sensitivity of this assay, in some experiments washed horse platelets replaced horse PRP, and Tyrode's buffer replaced PPP. The lowest concentrations of each PAF to cause irreversible and reversible platelet aggregation were recorded.

\section{Experiment 5: induction of thrombocytopaenia in mice by thrombin}

Twelve female Swiss Webster mice were bled for determination of control platelet concentrations. The mice were randomly assigned to 4 groups and injected into the lateral tail vein with $0,1,5$ or 20 iu thrombin in 0.5 mi Tyrode'sBSA diluent. After $30 \mathrm{~min}$, blood was sampled for a second platelet count which was expressed as a percentage of the control platelet concentration. The syringes were coded so that their contents were unknown until the completion of the experiment.

\section{Experiment 6: determination of mouse platelet sensitivity to PAF, ADP and thrombin}

The sensitivity of platelets from 5 mouse strains (Swiss Webster, CDl, C3H/He, C57BL/6, BALB/c) to PAF, ADP and thrombin was examined using a modified macroscopic haemagglutination procedure (Reisner et al., 1978). For each strain. blood samples from 5 mice were pooled and PRP was prepared. Aliquants of $100 \mu$ of PRP $\left(400 \times 10^{9}\right.$ platelets $\left./ 1\right)$ were placed on a mirrored plate. To each aliquant, a $10-\mu l$ sample of control buffer (either PBSBSA or Tyrode's buffer-BSA), thrombin $(0 \cdot 2 \mathrm{iu})$, ADP $(0.1 \mathrm{~mm})$ or one of the three forms of PAF $(0.2 \mathrm{~mm}$ and $3 \cdot 7 \mathrm{mM})$ was added. The droplets were mixed by gently tilting the plate back and forth continuously for 2 min and then detection of platelet clumping was recorded visually as either positive or negative. Each treatment was performed in duplicate.

\section{Statistical analysis}

A one-way analysis of variance was used to analyse the effect of PAF, thrombin or ADP injected into splenectomized mice. A two-way analysis of variance was used to analyse peripheral blood platelet concentrations in either intact or splenectomized mice, during the course of early pregnancy. Where appropriate, individual group means were compared using the Student-Newman-Keuls' test.

\section{Results}

\section{Determination of variation in platelet concentration (Exp. 1)}

Concentrations of platelets in blood samples obtained from each retro-orbital plexus of the same splenectomized mouse over 7 replicate samples ranged from $1450 \times 10^{9} / 1$ to $1515 \times 10^{9} / 1$ (mean $\left.1487 \times 10^{9} / 1\right)$ and from $1455 \times 10^{9} / 1$ to $1515 \times 10^{9} / 1$ (mean $1489 \times 10^{9} / 1$ ), respectively. The coefficients of variation within each sample population were 1.6 and $1.8 \%$, respectively.

\section{Determination of circulating platelet concentration during pregnancy (Exp. 2)}

Blood samples from intact pregnant Swiss Webster and C57BL/6 mice during the first 7 days of pregnancy, or nonpregnant mice of the same strains sampled concurrently, did not show significant differences in platelet concentration (Fig. 1). There was a trend, although not significant, for the platelet concentrations in pregnant animals to be lower than in nonpregnant animals in both Swiss Webster and C57BL/6 $(P \leqslant 0 \cdot 11, P \leqslant 0 \cdot 12$, respectively). The mean number of embryos observed in the reproductive tracts of pregnant mice was $11 \cdot 2$ for Swiss Webster and $8 \cdot 2$ for C57BL/6.

When splenectomized C57BL/6 mice were examined over the same period, significant changes in platelet concentrations, with respect to time, were not detected. Furthermore, although differences in the concentrations in pregnant and nonpregnant mice on any day were not significant, those in pregnant animals tended to be higher than in nonpregnant animals $(P \leqslant 0 \cdot 14 ;$ Fig. 2$)$. The mean number of embryos observed in the reproductive tracts of pregnant mice was $7 \cdot 3$. 
(a)

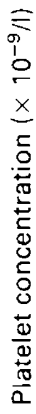

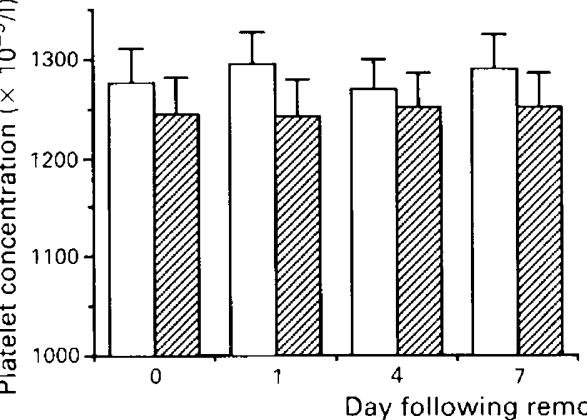

(b)

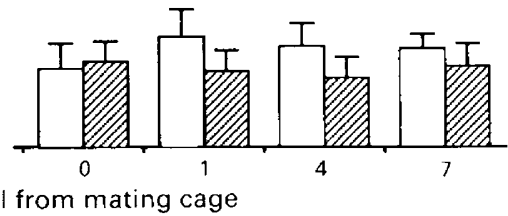

Fig. 1. Peripheral blood platelet concentrations in pregnant $(\mathbb{Z})$ and non-pregnant $(\square)$ Swiss Webster (a) and C57BL/6 (b) mice during early pregnancy. Each bar represents the mean\pm s.e.m. of the data from 10 mice.

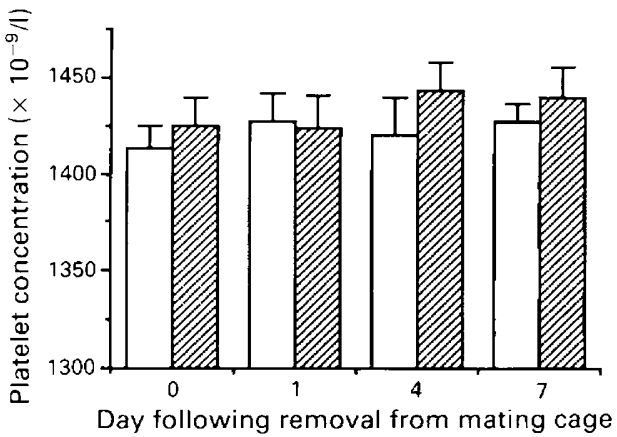

Fig. 2. Peripheral blood platelet concentrations in pregnant $(\mathbb{Z})$ and nonpregnant $(\square)$ splenectomized $\mathrm{C} 57 \mathrm{BL} / 6$ mice during early pregnancy. Each bar represents the mean \pm s.e.m. of the data from 3 mice.

\section{Evaluation of the splenectomized mouse bioassay (Exp. 3a)}

In the splenectomized mouse bioassay, none of the 3 PAF preparations at any concentration tested $(2 \cdot 3,4 \cdot 6$ and $9 \cdot 2 \mu \mathrm{M})$ induced a significant change in platelet concentrations with respect to either control or pre-injection concentrations in either strain of mouse used (Fig. 3). The preinjection platelet concentrations of splenectomized Swiss Webster and CD1 mice ranged from $1430 \times 10^{9} / 1$ to $1595 \times 10^{9} / 1$ and from $1463 \times 10^{9} / 1$ to $1650 \times 10^{9} / 1$, respectively.

\section{Estimation of changes in total numbers of circulating platelets during the splenectomized mouse bioassay (Exp. 3b)}

PAF treatment resulted in significant haemoconcentration in both Swiss Webster $(P<0.05)$ and $\mathrm{CD} 1$ mice $(P<0.0 \mathrm{I})$ and resulted in significant increases $(P<0.01)$ in platelet concentrations in both strains of mouse (Table 1). The control injections had no significant effect on either mouse strain. However, when post-injection concentrations were corrected for the change in blood volume, following PAF administration, no significant changes in platelet concentrations were observed. 

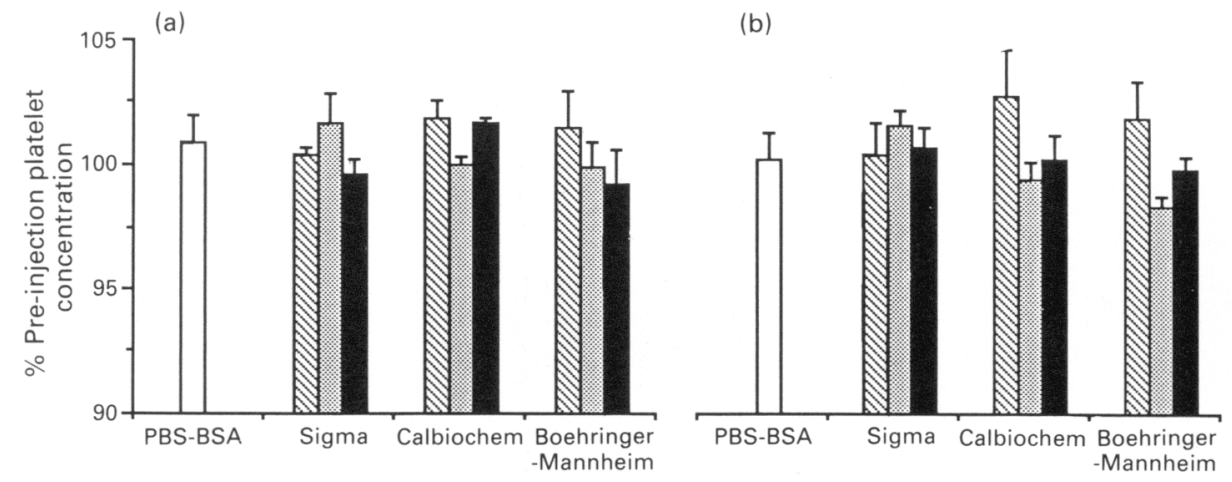

Source of PAF

Fig. 3. Alterations in blood platelet concentration in splenectomized (a) Swiss Webster and (b) CD1 mice following the i.p. administration of $0 \cdot 0 \mu \mathrm{M}(\square), 2 \cdot 3 \mu \mathrm{M}(\mathbb{\mathbb { N }}), 4 \cdot 6 \mu \mathrm{M}(\mathrm{W})$ and $9 \cdot 2 \mu \mathrm{M}(\mathbf{\square})$ platelet-activating factor (PAF) from 3 sources. Each bar is the mean \pm s.e.m. of the data from 3 mice. PBS-BSA = phosphate-buffered saline-bovine serum albumin.

\section{Aggregometric assay of the PAF preparations (Exp. 4)}

Aggregation of cow and horse (unwashed and washed) platelets occurred in the aggregometry assay using all 3 PAF preparations tested (Table 2). Cow platelets were the least sensitive to all 3 PAF preparations, while washed horse platelets were the most sensitive. The PAF obtained from Boehringer-Mannheim was consistently more potent than the other 2 preparations of PAF in all aggregometry assays.

PAF from Calbiochem which had been loaded into a syringe caused aggregation of unwashed horse platelets. The platelet aggregation response was irreversible at a final PAF concentration of $2 \cdot 0 \mathrm{nM}$, reversible at $1 \cdot 0$ and $0 \cdot 5 \mathrm{nM}$ and was not detected at $0 \cdot 3 \mathrm{~nm}$. PAF prepared at the same time but not loaded into a syringe produced identical results.

\section{Induction of thrombocytopaenia in mice by thrombin (Exp. 5)}

Thrombin induced a significant $(P \leqslant 0.01)$, dose-dependent reduction in the concentration of peripheral blood platelets following intravenous injection into intact Swiss Webster mice (Fig. 4). The mean ( \pm s.e.m.) pre-injection platelet concentration was $1329 \pm 29 \times 10^{9} / 1$.

\section{Determination of mouse platelet sensitivity to PAF, ADP and thrombin (Exp. 6)}

Similar results were obtained for all mouse strains tested (Table 3). None of the three preparations of PAF at either concentration aggregated isolated platelets. Both thrombin and ADP produced large platelet aggregates, while buffer controls had no effect on the platelets in the assay (Fig. 5, Table 3).

\section{Discussion}

The splenectomized mouse bioassay for the detection of PAF was developed using the Quackenbush strain of mouse (O'Neill et al., 1985a). Our study attempted to reproduce the bioassay using more-common mouse strains. However, three purified sources of PAF which were shown to be potent in-vitro aggregators of cow and horse platelets were unable to induce a thrombocytopaenic response in splenectomized mice of either the CDI or Swiss Webster strain when given in doses comparable to those given to Quackenbush mice (O'Neill, 1985c). It was considered 


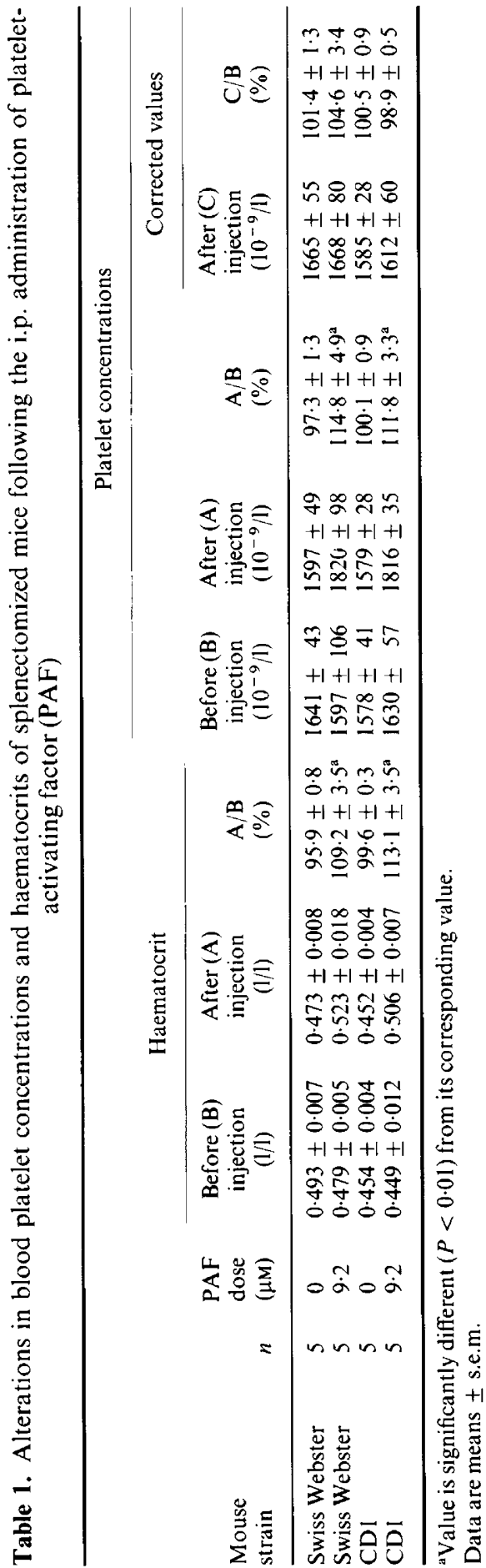




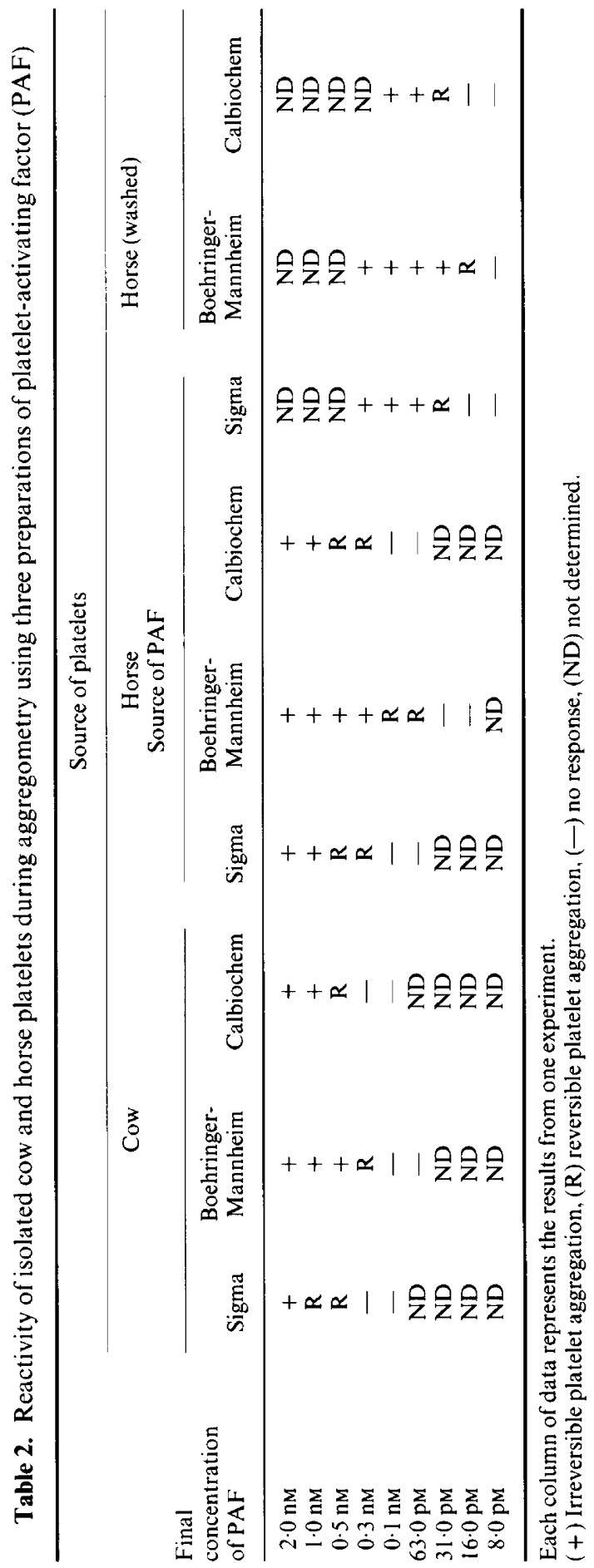




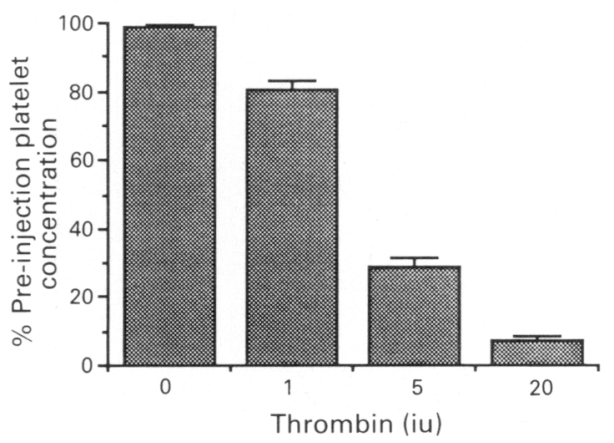

Fig. 4. Alterations in blood platelet concentration in intact Swiss Webster mice following the i.v. injection of thrombin. Each bar represents the mean \pm s.e.m. of the data from 3 mice.

Table 3. Reactivity of mouse platelet-rich plasma to several platelet-aggregating agents

\begin{tabular}{|c|c|c|c|c|c|}
\hline \multirow[b]{2}{*}{ Treatment $(10 \mu 1)$} & \multicolumn{5}{|c|}{ Mouse strain } \\
\hline & $\begin{array}{l}\text { Swiss } \\
\text { Webster }\end{array}$ & CDI & $\mathrm{C} 57 \mathrm{BL} / 6$ & $\mathrm{C} 3 \mathrm{H} / \mathrm{He}$ & $\mathrm{Balb} / \mathrm{c}$ \\
\hline \multicolumn{6}{|l|}{ Control } \\
\hline \multicolumn{6}{|l|}{ Phosphate-buffered saline } \\
\hline -bovine serum albumin (BSA) & $\ldots$ & - & $\ldots$ & - & - \\
\hline Tyrode’s-BSA & - & - & - & - & - \\
\hline \multicolumn{6}{|l|}{ Adenosine diphosphate } \\
\hline \multirow{2}{*}{\multicolumn{6}{|c|}{ Thrombin }} \\
\hline & & & & & \\
\hline$(0.2 \mathrm{iu})$ & + & + & + & + & + \\
\hline \multicolumn{6}{|l|}{ PAF } \\
\hline \multicolumn{6}{|l|}{ Sigma } \\
\hline$(0 \cdot 2 \mathrm{~mm})$ & - & - & - & - & $\ldots-.$. \\
\hline$(3.7 \mathrm{~mm})$ & - & - & - & - & -- \\
\hline \multicolumn{6}{|l|}{ Boehringer-Mannheim } \\
\hline$(0 \cdot 2 \mathrm{~mm})$ & - & - & - & - & - \\
\hline$(3.7 \mathrm{~mm})$ & - & - & - & - &.-- \\
\hline \multicolumn{6}{|l|}{ Calbiochem } \\
\hline$(0.2 \mathrm{~mm})$ & - & - & - & - & - \\
\hline$(3.7 \mathrm{~mm})$ & - & - & - & - & - \\
\hline
\end{tabular}

(+) Platelet aggregation, (--) no response.

that this could have been due to either genetic differences between mice or a lack of technical competence in platelet counting. Since Quackenbush mice were not available in this laboratory, the genetic differences which might exist between this mouse strain and strains used in this study could not be examined. However, accuracy in platelet counting, the activity of the PAF preparations in other assays and the thrombocytopaenic response of the mice to agents other than PAF were each evaluated.

To rule out technical problems associated with the bioassay, the collection procedures for platelets were standardized, since variability in peripheral blood platelet concentrations $>5 \%$ is detrimental to the bioassay (O'Neill et al., 1987). Blood was collected in the same way from all mice from the retro-orbital plexus, and was not allowed to remain in ammonium oxalate for $>5 \mathrm{~min}$ prior to loading onto a haemocytometer. Platelet counting was performed by the same individual to eliminate observer variation. Replicate efficiency was acceptable, since the coefficient of variation for platelet concentrations from 2 successive blood samples taken from one animal and 

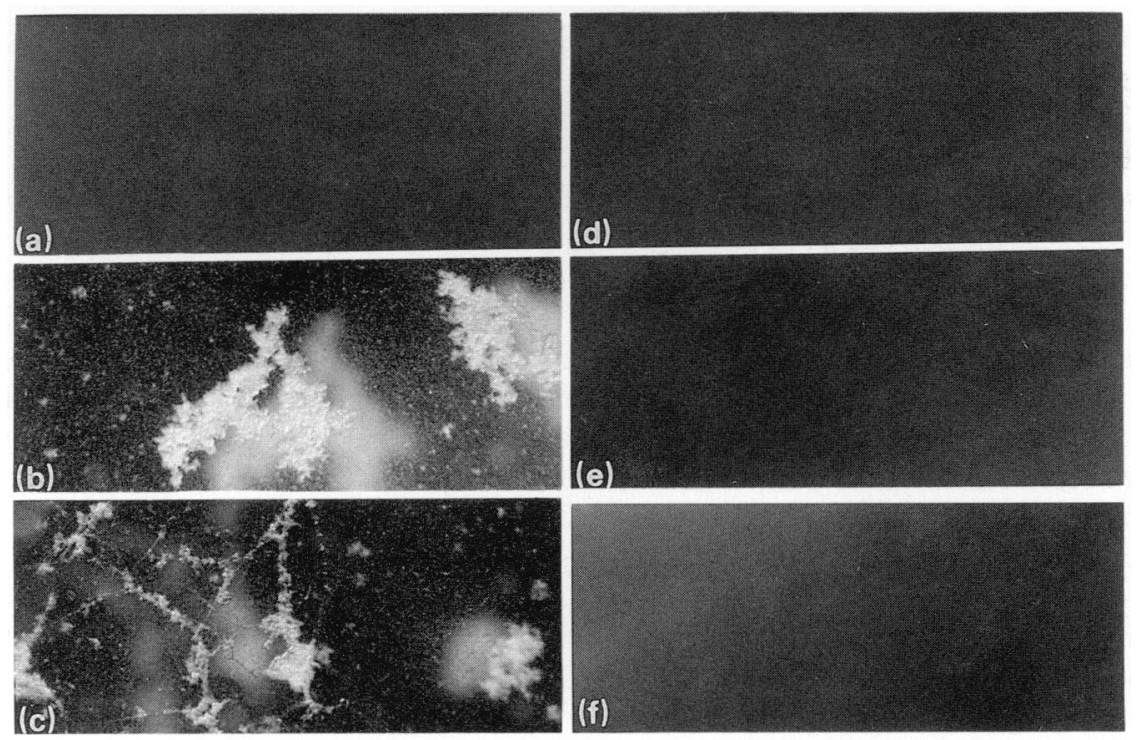

Fig. 5. Photomicrograph of isolated Swiss Webster mouse platelets (magnification $\times 60$ ) following the addition of (a) phosphate-buffered saline-bovine serum albumin. (b) $0.1 \mathrm{~mm}$ adenosine-diphosphate. (c) 0.2 iu thrombin. (d) $0.2 \mathrm{~mm}$ Sigma platelet-activating factor (PAF), (c) 0.2mm Boehringer-Mannheim-PAF and (f) $0 \cdot 2 \mathrm{~mm}$ Calbiochem-PAF.

loaded into 7 haemocytometers was $<2 \%$ in both cases. Also, the range of platelet concentrations reported in this study was $958-1650 \times 10^{9} / 1$ compared with the published range of 1330 $1800 \times 10^{9} / 1$, in different strains of mice (O`Neill, 1985a).

The method of preparing the purified PAF for injection was identical to that described by O'Neill. (1985c) using BSA as a carrier molecule for PAF in PBS. Also, all PAF preparations used in the bioassay were shown to be potent in-vitro aggregators of platelets from other species. Finally, a thrombocytopaenic response was readily detected in Swiss Webster mice injected with thrombin in the present study. This suggests that the negative results obtained in the bioassay were caused by a lack of effect of PAF in the mouse strains used and were not due either to technical difficulties in platelet counting or to an inability of the mice to exhibit thrombocytopaenia. Experiment $3 \mathrm{~b}$ was performed in response to a suggestion that thrombocytopaenic responses could be masked by concomitant haemoconcentration in the strains of mice that we examined. PAF did, indeed, cause haemoconcentration in both the Swiss Webster and CD1 mice in this experiment. Injections of PAF also increased platelet concentrations to a much larger extent than had been observed in Exp. 3a. The reason for this is unknown, but it may be significant that Exp. 3 b was carried out 2 years after Exp. 3a and outbred strains of mice were used. However, after correcting for the haemoconcentration, it was evident that PAF treatment had not reduced the total number of platelets in the circulation, implying that platelet activation had not occurred. Thus, although estimates of changes in blood volumes were not performed in the other experiments of this study, it seems unlikely that they could account for the lack of thrombocytopaenic responses. It should also be stressed that the criterion of response in the bioassay has been reported to be a change in platelet concentration, not in total numbers of circulating platelets.

Conflicting results have recently been reported using the splenectomized mouse bioassay. Keefer et al. (1989) suggested that thrombocytopaenia can only be detected at a very low and narrow dose range of PAF $(0.755 .0 \mathrm{ng})$ in their particular mouse strain, which is $50-300$ times lower than the lowest dose reported by O`Neill (1985c). Other researchers using a Swiss mouse strain have reported that only doses of $\geqslant 1 \mu \mathrm{g}$ PAF have the ability to elicit a thrombocytopaenic 
response when injected i.p. (Amiel et al., 1989). It is therefore possible that for each of the 5 mouse strains studied the PAF concentrations used were outside the effective dose range.

Both O'Neill (1985c) and Roberts et al. (1987) have demonstrated thrombocytopaenia in pregnant $\mathrm{C} 57 \mathrm{BL} / 6$ mice. This is contradictory to our findings and the discrepancy is not due to fewer embryos in the reproductive tract of the mice in our study. One explanation for these conflicting data could be that the inbred line (C57BL/6; no source listed) used by O'Neill and by Roberts $e t$ al. (at the same institution) had undergone genetic drifting resulting in subline divergence (Bailey, 1982).

Another explanation for the failure to observe thrombocytopaenia in either Swiss Webster or C57BL/6 mice during early pregnancy could be the insensitivity of rodent platelets to PAF, as has been described in CD1 mice (Namm et al., 1982) and rats (Inarrea et al., 1984). The present study confirmed PAF insensitivity of isolated CDI platelets and demonstrated similar PAF insensitivity in platelets isolated from Swiss Webster, BALB/c, C3H/He and C57BL/6 mice using the macroscopic technique of direct observation of platelet aggregation on mirrored plates. Although isolated platelets from all strains of mice tested were insensitive to PAF, they retained their responsiveness to the known platelet-aggregating factors ADP and thrombin, indicating successful platelet isolation procedures.

It has been suggested that a physiological role for the release of PAF from early embryos is to enhance blastocyst growth due to the release of factors from platelets. This is based on observations that blastocyst outgrowth, the in-vitro equivalent to nidation, occurs only in the presence of whole serum and not with serum derived from platelet-depleted plasma (O'Neill, 1985a; O'Neill et al., 1989). This conclusion is not supported by evidence showing that the products of activated platelets are detrimental to the development of ICR mouse embryos in vitro (Jinno et al., 1987).

The difficulties of obtaining a mouse strain in which the platelets are sensitive to PAF, combined with the reported low sensitivity of the bioassay (O'Neill et al., 1985a; O'Neill, 1987), make the splenectomized mouse bioassay largely unsuitable for the study of PAF during early pregnancy. Also, recent studies by Amiel et al. (1989) cast some doubt on the ability to forecast embryo viability using the measurement of PAF. In addition to finding embryo-derived PAF production in unfertilized oocytes, they question whether embryo-derived PAF is indeed homologous with PAFacether as claimed by Collier et al. (1988), as no PAF activity was detected in the very sensitive aggregometry assay, using culture media which had tested positive for embryo-derived PAF using the mouse bioassay. Milligan \& Finn (1990) have recently reported that PAF failed to induce decidualization in mice and, contrary to Spinks \& O'Neill (1988), showed that the PAF antagonist (SRI 63-441) was unable to inhibit implantation. Since this study was completed, Smal et al. (1990) have reported their inability to detect PAF production by 2-cell embryos, compact morulae, or blastocysts from $\mathrm{C} 57 \mathrm{BL} / 6 \mathrm{~J} \times \mathrm{CBA} / \mathrm{H}$ mice using either aggregometry or a highly sensitive radioimmunoassay for PAF.

The contradictions among these published reports, together with the present observations of a lack of sensitivity of platelets from several strains of mice to PAF, lead us to conclude that any critical role for PAF in early pregnancy may be less universal and/or more complex than suggested by earlier studies.

This study was funded by grants from NSERC Canada, Semex Canada, Agriculture Canada and The Canadian Association of Animal Breeders. We thank S. Crane for technical assistance, D. L. Shepherd for photography and P. Fowle for manuscript preparation.

\section{References}

Amiel, M.L., Duquenne, C., Benveniste, J. \& Testart, J. (1989) Platelet aggregating activity in human embryo culture media free of PAF-acether. Human Reprod. 4, $327-330$.
Bailey, D.W. (1982) How pure are inbred strains of mice? Immunol. Today 3, 210-214.

Betteridge, K.J. (1986) Increasing productivity in farm animals. In Reproduction in Mammals, Vol. 5, 
pp. 1-47. Eds C. R. Austin \& R. V. Short. Cambridge University Press, Cambridge.

Brecher, G. \& Cronkite, E.P. (1950) Morphology and enumeration of human blood platelets. J. Applied Physiol. 3, 365377.

Collier, M., O’Neill, C., Ammit, A.J. \& Saunders, D.M. (I988) Biochemical and pharmacological characterization of human cmbryo-derived platelet-activating factor. Hum. Reprod. 3, 993998.

Inarrea, P., Gomez-Cambronero, J., Nieto, M. \& Sanchez Crespo, M. (1984) Characteristics of the binding of platelet-activating factor to platelets of different animal species. European J. Pharmacol. 105, 309-315.

Jinno, M., lida, E. \& Iizuka, R. (1987) A detrimental effect of platelets on mouse embryo development. $J$. In Vitro Fert. \& Emb. Transf. 4, 324-330.

Keefer, C.L., Camoratto, A.M. \& Langford, K.G. (1989) Detection of synthetic and embryo-derived plateletactivating factor by the splenectomized mouse assay. Biol. Reprod. (Suppl.) 40,67.

Milligan, S.R. \& Finn, C.A. (1990) Failure of plateletactivating factor (PAF-acether) to induce decidualization in mice and failure of antagonists of PAF to inhibit implantation. J. Reprod. Fert. 88, 105-112.

Namm, D.H., Tadepalli, A.S. \& High, J.A. (1982) Species specificity of the platelet response to 1-o-alkyl-2acetyl-sn-glycero-3-phosphocholine. Thrombosis Res. 25, 34 I - 350.

O'Neill, C. \& Saunders, D.M. (1984) Assessment of embryo quality. Lancet, ii, 1035.

O'Neill, C. (1985a) Thrombocytopaenia is an initial maternal response to fertilization in mice. $J$. Reprod. Fert. 73, 559-566.

O'Neill, C. (1985b) Partial characterization of the embryo-derived platelet-activating factor in mice. $J$. Reprod. Fert. 75, 375-380.

O'Neill, C. (1985c) Examination of the causes of early pregnancy-associated thrombocytopaenia in mice. $J$. Reprod. Fert. 73, 567-577.

O'Neill, C. (1987) Embryo-derived platelet activating factor: a preimplantation embryo mediator of maternal recognition of pregnancy. Dom. Anim. Endocr. 4, $69 \cdots 85$.
O’Neill, C., Collier, M., Ryan, J.P. \& Spinks, N.R. (1989) Embryo-derived platelet-activating factor. J. Reprod. Fert., Suppl. 37, 19-27.

O'Neill, C., Gidley-Baird, A.A., Pike, I.L. \& Saunders, D.M. (1987) Use of a bioassay for embryo-derived platelet-activating factor as a means of assessing quality and pregnancy potential of human embryos. Fert. Steril. 47, 969-975.

O'Neill, C., Gidley-Baird, A.A., Pike, I.L., Porter, R.N., Sinosich, M.J. \& Saunders, D.M. (1985b) Maternal blood platelet physiology and luteal-phase endocrinology as a means of monitoring pre- and postimplantation embryo viability following in vitro fertilization. J. In Vitro Fert. \& Emb. Transf. 2, 87-93.

O'Neill, C., Pike, I.L., Porter, R.N., Gidley-Baird, A.A., Sinosich, M.J. \& Saunders, D.M. (1985a) Maternal recognition of pregnancy prior to implantation: methods for monitoring embryonic viability in vitro and in vivo. Ann. N.Y. Acad. Sci. 442, 429-439.

Reisner, H.M., Katz, H.J., Goldin, L.R., Barrow, E.S. \& Graham, J.B. (1978) Use of a simple visual assay of Willebrand Factor for diagnosis and carrier identification. Brit. J. Haematol. 40, 339-350.

Roberts, T.K., Adamson, L.M., Smart, Y.C., Stanger, J.D. \& Murdoch, R.N. (1987) An evaluation of peripheral blood platelet enumeration as a monitor of fertilization and early pregnancy. Fert. Steril. 47, 848-854.

Smal, M.A., Dziadek, M., Cooney, S.J., Attard, M. \& Baldo, B.A. (1990) Examination for plateletactivating factor production by preimplantation mouse embryos using a specific radioimmunoassay. J. Reprod. Fert. 90, 419425.

Spinks, N.R. \& O'Neill, C. (1987) Embryo-derived platelet-activating factor is essential for establishment of pregnancy in the mouse. Lancet, i, 106-107.

Spinks, N.R. \& O'Neill, C. (1988) Antagonists of embryo-derived platelet-activating factor prevent implantation of mouse embryos. J. Reprod. Fert. 84, 89-98.

Suquet, C.M. \& Leid, R.W. (1983) Aggregation of equine platelets by PAF (platelet activating factor). Inflammation 7, 197-203.

Received 4 January 1991 